\title{
Technical Efficiency Analysis of Fiji's Sugar Industry: An Application of the Stochastic Frontier Production Function Approach
}

\section{Mahendra Reddy}

Centre for Development Studies, University of the South Pacific

\section{John F Yanagida}

Department of Agricultural Resource Economics, University of Hawaii

\section{ABSTRACT}

Small developing countries have for long acquired significant benefits through preferential trading arrangements. However, these benefits have led to a proliferation of inefficient industries in the recipient countries. With the recent changes in the GATT, these inefficient industries may close and thus lead to major economic and social problems in the recipient countries. This paper utilizes the frontier production function approach to examine the efficiency status of Fiji's sugar industry. The analysis reveals that a significant level of inefficiency exists at the farm level of Fiji's sugar industry. Some of the factors that were found to effect the level of efficiency are farming status, land class and ethnicity. These factors are then used to derive policy implications.

JEL Q 10

\section{INTRODUCTION}

Efficiency and productivity analysis of agricultural enterprises has always been a major focus for applied economists. This role has been accentuated given the recent changes in the General Agreements on Tariffs and Trade (GATT) which has brought agriculture into the world free market. A key argument for trade liberalization resulting from the Uruguay Round (UR) of the GATT is that it would lead to a more efficient resource allocation in the world (Devadoss and Kropf, 1996). This implies that industries, which are inefficient, will be pushed out of the market and resources, which were previously tied up in these industries, will now be allocated to alternative enterprises. Developing countries, especially those, 
which, in the past have made enormous amount of industry specific capital investments, are now scrambling in search of avenues to increase productivity of those industries. Fiji's sugar industry is now in this situation. This industry over the years has received substantial benefits from the Sugar Protocol of the Lome convention where it gained access to the European market at subsidized prices, which continue to be higher than the world free market price. The short run impact of a fall in price, especially on peasant farmers of developing countries can lead to a major crisis, such as increased poverty. It is in this regard that efficiency analysis, which identifies the level of inefficiency and the determinants of this inefficiency, can play a very crucial role in policy formulation that can be used to avert this crisis.

This paper uses standard neoclassical economic theory to evaluate economic efficiency of Fiji's sugar cane industry. A stochastic frontier production function approach is utilized taking into account the implications of production characteristics of the two ethnic communities, land tenure system and farm sizes. Results from the study will be used to help formulate policies for Fiji's sugar industry. For countries with similar problems and farming systems, the policy implications derived here could be utilized in those countries.

\section{LITERATURE REVIEW}

This paper utilizes the stochastic frontier production function method proposed independently by Aigner, Lovell and Schmidt (1977) and Meeusen and van den Broeck (1977). This model has been applied and modified in numerous studies including Battese and Corra (1977), Lee and Tyler (1978), Stevenson (1980), Pitt and Lee (1981), Jondrow et al. (1982), Kalirajan (1981), Bagi and Huang (1983), Kalirajan and Flinn (1983), Huang and Bagi (1984), Schmidt and Sickles (1984), Waldman (1984) and Coeli (1985), Battese and Coelli (1988), Battese et al. (1989), and Battese and Coelli $(1992,1993)$. Bauer (1990) provides a summary of developments in the econometric estimation of frontiers.

There has also been.wide application of this methodology in the agricultural industries. Battese (1992), Bravo-Ureta and Pinheiro (1993), and Coelli (1995) provide surveys of applications in this field. Some of the recent studies include Battese and Coelli (1995), Trewin et al. (1995), Battese et al. (1996), Coelli and Battese (1996), Bravo-Ureta and Pinheiro (1997), and Heshmati and Kumbhakar, (1997). 
Battese and Coelli (1995) specify a stochastic frontier production function and a technical effects model for which all parameters involved can be estimated simultaneously. The model is estimated with a panel of fourteen farmers over a ten year period from the village of Aurepalle in India. Trewin et al. (1995) utilized the stochastic frontier model to obtain an estimate of technical efficiency over time of rice farmers in West Java, Indonesia. The mean technical efficiency obtained for both wet and dry season farmers was approximately 15\%. One of the key policy implications drawn from this study was the use of better extension practices that would enhance utilization of correct farming practices by farmers. Battese et al. (1996) apply a single stage model for estimating technical inefficiencies of production for wheat farmers in four districts of Pakistan. Results from the analysis indicate a mean technical efficiency ranging from $57 \%$ to $79 \%$ for the four districts. Apart from some variables having mixed results, the two key variables, age and education had consistent effects on technical inefficiency for all four districts. With respect to age, older farmers displayed lower levels of technical inefficiency. For education, increases in the years of formal schooling had a negative effect on the level of technical inefficiency. Coelli and Battese (1996) applied the stochastic frontier methodology along with a model of technical efficiency effects to Indian farmers. The results of the study showed the three villages in the study had an average technical efficiency of $73 \%$. The technical effects model suggests an inverse relationship between inefficiency and variables such as farm size and time. This implies that technical inefficiency has declined over time in the study area. With respect to farm size, smaller farms had a higher level of technical inefficiency relative to larger farms. Bravo-Ureta and Pinheiro (1997) applied the frontier production function approach to peasant farmers in the Dominican Republic. Results from the study reveal that peasant farmers in the Dominican Republic had mean technical, allocative and economic efficiencies of $70 \%, 44 \%$ and $31 \%$ respectively. An analysis on the determinants of technical efficiency point to two key factors, farm size and farmer's age. Smaller farms are associated with higher levels of inefficiency relative to larger farms. For age, younger farmers displayed a greater level of efficiency relative to older farmers. Heshmati and Kumbhakar, (1997) applied this approach to pseudo panel data for Swedish crop farmers. Results from the study found that the technical efficiency of farmers varied from $62 \%$ to $71 \%$. This study also found that small farms had the highest level of inefficiency. 


\section{THEORETICAL MODEL}

The stochastic frontier production function can be expressed as follows:

$$
Y_{i}=x_{i} \beta+E_{i,}
$$

and

$$
E_{i}=V_{i}-U_{i}
$$

where $Y_{i}$ denotes output for the ith sample firm $(i=1,2, \ldots, N) ; x_{i}$ is a $(1 \times k)$ vector of inputs associated with ith sample firm; $\beta$ is a $(k \times 1)$ vector of the coefficients for the associated independent variables in the production function; $V_{i}$ are assumed to be independent and identically distributed as $N\left(0, \sigma_{\mathrm{v}}^{2}\right)$, independently distributed of $\mathrm{U}_{i} ; \mathrm{U}_{i}$ are non-negative, technical inefficiency effects, which are assumed to be independently and identically distributed non-negative random variables, which can follow such distributions as half normal, truncated normal, exponential and gamma distributions (Aigner, et al. 1977; Greene, 1980; Meeusen and Van den Broeck, 1977).

The maximum likelihood estimation of equation (1) yields consistent estimators for $\beta, \lambda$, and $\sigma^{2}$, where $\beta$ is a vector of unknown parameters, $\lambda=\sigma_{u} / \sigma_{v}$ and $\sigma^{2}=\sigma_{u}$ ${ }^{2}+\sigma_{v}{ }^{2}$. Jondrow et al. (1982) have shown that inferences about the technical inefficiency of individual farmers can be made by considering the conditional distribution of $u$ given the fitted values of $\varepsilon$ and the respective parameters. Based on the assumptions: $\mathrm{v} \sim \mathrm{N}\left(0, \sigma_{\mathrm{v}}{ }^{2}\right), \mathrm{u} \sim\left|\mathrm{N}\left(0, \sigma_{13}{ }^{2}\right)\right|$, and $\mathrm{E}(\mathrm{v})=0$, he computed the conditional mean of $u_{i}$ given $\varepsilon_{i}=v_{i}-u_{i}$ as a measure of technical efficiency as:

$$
E\left(u_{i} \mid \varepsilon_{i}\right)=\sigma^{*}\left[\frac{f^{*}\left(\varepsilon_{i} \lambda / \sigma\right)}{1-F^{*}\left(\varepsilon_{i} \lambda / \sigma\right)}-\frac{\varepsilon_{i} \lambda}{\sigma}\right],
$$

where $\mathrm{F}^{*}$ and $\mathrm{F}^{*}$ are, respectively standard normal density and cumulative distributions evaluated at $\varepsilon_{i} \lambda / \sigma, \sigma^{2}=\sigma_{v}{ }^{2}+\sigma_{u}{ }^{2}, \lambda=\sigma_{u} / \sigma_{v}$, and $\sigma^{*}=\sigma_{u}{ }^{2} \sigma_{v}{ }^{2} / \sigma^{2}$. The estimates of $\sigma^{2}, \lambda$, and parameter vector $\beta$ are obtained by maximum likelihood estimation. Jondrow et al. (1982) also derived a similar formula for the exponential distribution while Greene (1990) derived a formula for the gamma distribution.

Replacing $\varepsilon, \sigma \cdot$, and $\lambda$ by their estimates in equation (1) and (3), we derive the estimates for $v$ and $u$. Subtracting $v$ from both sides of equation (1) yields the stochastic production frontier: 


$$
\mathrm{Y}^{*}=f\left(\mathrm{X}_{i} ; \beta\right)-u=\mathrm{Y}-v_{3}
$$

where $\mathrm{Y}^{*}$ is defined as the farm's observed output adjusted for the statistical noise contained in $v$ (Bravo-Ureta and Rieger, 1991 and Bravo-Ureta and Pinheiro, 1997).

\section{EMPIRICAL MODEL}

The specification of the empirical model requires the choice of an appropriate functional form. In this study, the Cobb-Douglas functional form was chosen since a more general functional form like the translog model may be not be possible to estimate due to the large number of explanatory variables examined in this study. Studies on the impact of functional form on efficiency estimates such as Kopp and Smith (1980) conclude that functional specification has very little impact on the estimated efficiency.

Therefore, the stochastic frontier production function for sugarcane farmers of a given farm size and ethnic group is assumed to be:

$\ln Y_{i}=\beta_{0}+\beta_{1} \ln (K)+\beta_{2} \ln (L)+\beta_{3} \ln (F L)+\beta_{4} \ln (H L)+\beta_{5} \ln (B H)+$ $\beta_{6} \ln (\mathrm{TH})+\beta_{7} \ln (\mathrm{FQ})+\beta_{8} \ln (\mathrm{CQ})+\mathrm{V}_{\mathrm{i}}-\mathrm{U}_{\mathrm{i}}$

where the subscripts i refers to the ith farmer;

Ln Denotes natural logarithm;

$Y \quad$ Denotes quantity of sugarcane harvested (in tons);

$\mathrm{K}$ Denotes capital (total value of farm equipment's in $\mathrm{F} \$$ );

L Denotes land area under crop (in acres);

FL Denotes total amount of family labor used (in hours);

HL Denotes total amount of hired labor used (in hours);

$\mathrm{BH}$ Denotes total amount of bullock labor used (in hours for a pair of bullocks);

TH Denotes tractor use (in hours);

FQ Denotes quantity of fertilizer applied (in number of $10 \mathrm{~kg}$ bags);

$\mathrm{CQ}$ Denotes quantity of pesticide used (in number of 4 liter containers); and 
$V_{i}$ are assumed to be independently distributed normal random variables with mean, zero, and variance, $\sigma^{2}$, independently distributed of $U_{i} ; U_{i}$ are non-negative technical inefficiency effects, which are assumed to be independently distributed and arise from the truncation (at zero) of the normal distribution with variance, $\sigma^{2}$, and mean, $\mu_{i}$ defined by

$\mu_{3}=\delta_{i}+\delta_{1}\left(\mathrm{AG}_{i}\right)+\delta_{2}\left(\mathrm{SY}_{i}\right)+\delta_{3}\left(\mathrm{FST}_{1}\right)+\delta_{4}\left(\mathrm{LT}_{\mathrm{i}}\right)+\delta_{5}\left(\mathrm{LC}_{\mathrm{i}}\right)+\delta_{6}\left(\mathrm{FS}_{\mathrm{i}}\right)+\delta_{7}\left(\mathrm{ETH}_{\mathrm{i}}\right)$

where:

AG

denotes the age of primary decision-maker (in years);

SY represents the maximum years of formal schooling of the primary decision maker;

FST farming status (dummy variable used, 1 if full time and 0 if part time);

LT land tenure system (discontinuous variable used, 0 for native land, 1 for crown land and 2 for freehold land); and

LC land class (discontinuous variable used, 0 for $1^{\text {st }}$ class arable, 1 for $2^{\text {nd }}$ class arable, 2 for $3^{\text {rd }}$ class arable and 3 for marginal arable) ';

FS farm size measured in acres; and

ETH ethnicity of farmer measured using a dummy variable ( 0 for Fijian farmer and 1 for an Indian farmer).

The $\beta$ and $\delta$ coefficients are unknown parameters to be estimated, together with variance parameters which are expressed in terms of

$$
\begin{gathered}
\sigma_{s}{ }^{2}=\sigma_{s}{ }^{2}+\sigma^{2} \text { and } \\
\gamma=\sigma^{2} / \sigma_{s}{ }^{2}
\end{gathered}
$$

where the parameters have values between zero and one.

A priori, the signs of all production function parameters specified above are expected to be positive. With regard to the inefficiency model, all variables except the land class variable are expected to have a negative sign. Generally, a negative sign with respect to age implies that with increasing age, farmers become more experienced and thus become more efficient. The education variable's negative sign implies that higher education will lead to a more efficient resource allocation and thus an increase in efficiency. The land tenure variable, as specified, is expected to have a negative sign. The first type of land, native land, is leased land, which have a high degree of uncertainty with regard to the renewal of land leases. 
The second type of lease, crown land, is regarded as better in terms of lease renewal given that it is state owned. The third type of land is the freehold land, which is devoid of any risk and uncertainty. Therefore this variable is expected to have a negative sign. The land class variable is divided into 4 classes with class 1 designating the most arable land while class 4 being the poorest land. In this case, the expected sign of this variable is positive. Farm size variable is expected to have a negative sign indicating that as farm size increases, inefficiency will decline. The ethnicity variable is used to examine if there is any significant differences in efficiency between the two ethnic farming groups.

The inefficiency model can only be estimated if the inefficiency effects are stochastic and have a particular distributional specification. Therefore the null hypothesis that the inefficiency effects are not stochastic (Ho: $\gamma=0$ ) will be tested. Furthermore, the null hypothesis that the coefficients of the variables in the model for the inefficiency effects are zero $\left(\mathrm{H}_{0}: \delta_{1}=\ldots=\delta_{4}=0\right)$ will also be tested. These null hypothesis are tested using the generalized likelihood-ratio statistic, $\lambda$, defined by:

$\lambda=-2 \ln \left[\mathrm{L}\left(\mathrm{H}_{0}\right) / \mathrm{L}\left(\mathrm{H}_{1}\right)\right]$

where $\mathrm{L}\left(\mathrm{H}_{0}\right)$ and $\mathrm{L}\left(\mathrm{H}_{1}\right)$ are values of the likelihood function under the specifications of the null and alternative hypothesis, $\mathrm{H}_{0}$ and $\mathrm{H}_{3}$.

\section{DATA}

The data for this study were obtained from a survey carried out over a 2 month period. A stratified random sampling approach was used to collect the data where the stratas were defined primarily by the two ethnic communities and to some extent by different farm sizes. A total of 397 farmers were included in this analysis. This sample comprised of 319 Indian farmers and 78 Fijian farmers. More details on sampling framework and data collection are presented in Reddy (1998). 


\section{EMPIRICAL RESULTS AND DISCUSSION}

OLS estimates of the production function were used as a basis to determine the goodness of fit of the model (Appendix 1). The model displayed a fairly good fit with an adjusted $\mathrm{R}^{2}$ value of $88 \%$. Maximum likelihood estimate of the frontier production function were obtained using the Frontier 4.1 program (Coelli, 1994). The model was estimated under the two common specifications for the one-sided error term, the half normal distribution and the general truncated normal distribution. A likelihood ratio test was used to determine which functional form of the one-sided error term was more appropriate. Based on these results, the null hypothesis of a half normal distribution for the error term was rejected. The maximum likelihood estimates, of the frontier production function is presented in Table 1. The signs of all the variables in the production function conform to a priori expectations. The $\gamma$ parameter value is close to 1.0. This implies that the technical inefficiency effects are significant in the stochastic frontier model and that the traditional production function, with no technical inefficiency effects, is not an adequate representation of the data. The null hypothesis that the inefficiency effects are not stochastic was also rejected at the $5 \%$ level of significance. Similarly, a likelihood ratio test for the null hypothesis that all the coefficients of the inefficiency model are equal to zero was also rejected. This implies that the explanatory variables have a significant effect on the level of the technical inefficiency.

Table 1: Maximum-likelihood Estimates for Parameters of the Stochastic Frontiers and Inefficiency Models for Sugarcane Farmers in Fiji, 1997

\begin{tabular}{|l|c|c|}
\hline Variable & Parameter & Estimate \\
\hline Constant & $\beta_{0}$ & 1.281 \\
& & $(0.036)^{*}$ \\
\hline Capital & $\beta_{1}$ & 0.031 \\
& & $(0.005)^{*}$ \\
\hline Land & & 0.664 \\
& & $(0.027)^{*}$ \\
\hline Family Labor & $\beta_{2}$ & 0.034 \\
& & $(0.016)^{*}$ \\
\hline Hired labor & $\beta_{3}$ & 0.014 \\
& & $(0.007)$ \\
\hline
\end{tabular}


Table 1 continuted

\begin{tabular}{|c|c|c|}
\hline Variable & Parameter & Estimate \\
\hline Bullock hours & $\beta_{4}$ & $\begin{array}{c}0.046 \\
(0.009)^{*}\end{array}$ \\
\hline Tractor hours & $\beta_{5}$ & $\begin{array}{c}0.038 \\
(0.008)^{*}\end{array}$ \\
\hline Fertilizer quantity & $\overline{\beta_{6}}$ & $\begin{array}{c}0.073 \\
(0.011)^{*}\end{array}$ \\
\hline Chemical quantity & $\beta_{7}$ & $\begin{array}{c}0.056 \\
(0.016)^{*}\end{array}$ \\
\hline \multicolumn{3}{|l|}{ Inefficiency Model } \\
\hline Constant & $\delta_{0}$ & $\begin{array}{l}-0.147 \\
(0.154)\end{array}$ \\
\hline Age & $\delta_{1}$ & $\begin{array}{c}0.003 \\
(0.002) \\
\end{array}$ \\
\hline Education & $\delta_{2}$ & $\begin{array}{l}-0.002 \\
(0.005)\end{array}$ \\
\hline Farming status & $\delta_{3}$ & $\begin{array}{c}-0.188 \\
(0.047)^{*}\end{array}$ \\
\hline Land Tenure & $\bar{\delta}_{4}$ & $\begin{array}{c}0.024 \\
(0.023)\end{array}$ \\
\hline Land class & $\delta_{5}$ & $\begin{array}{c}0.196 \\
(0.059)^{*}\end{array}$ \\
\hline Farm Size & $\delta_{6}$ & $\begin{array}{l}-0.012 \\
(0.007)\end{array}$ \\
\hline Ethnicity & $\delta_{7}$ & $\begin{array}{l}-0.355 \\
(0.084)^{*}\end{array}$ \\
\hline \multirow[t]{2}{*}{ Variance parameters } & $\sigma_{\mathrm{s}}{ }^{2}$ & $\begin{array}{c}0.029 \\
(0.004)^{*}\end{array}$ \\
\hline & $\gamma$ & $\begin{array}{c}0.771 \\
(0.045)^{*}\end{array}$ \\
\hline Log-likelihood Function & & 361.79 \\
\hline Number of iterations & & 34 \\
\hline $\begin{array}{l}\text { Mean Technical Efficiency } \\
(\%)\end{array}$ & & 94.41 \\
\hline
\end{tabular}

Note: (a) Figures in parentheses are asymptotic standard errors.

(b) * Denotes $5 \%$ level of significance. 
Results from the analysis reveal that on an average, the sugarcane farmers in Fiji are operating with $5.6 \%$ technical inefficiency (see Table 1). With such a large magnitude of inefficiency level, an investigation of the factors that may cause such level of inefficiency can help for policy making. Therefore, the inefficiency models' primary aim was to identify those socioeconomic and other land characteristics, which contribute to technical inefficiency. The results, presented in Table 1, are again interesting. The inefficiency model consists of seven variables, namely age, education, farming status, land tenure and land class, farm size and ethnicity. The age variable is expected to have a negative sign implying that older farmers are more experienced and thus will be more efficient. The results obtained are in contrary. The positive sign of this variable implies that the effects of old age and poor health conditions override the experience factor of the farmers. The education variable has the result expected. The negative sign implies that, farmers with more years of formal education are associated with a higher level of efficiency.

The positive sign of the land class variable indicates that poor land used in sugarcane farming has contributed to increased inefficiency. The farming status variable indicates that part-time farmers are associated with higher levels of inefficiency. The land tenure variable has a positive sign, however, this variable has an insignificant effect on farm efficiency. The insignificant coefficient for this variable may be due to the fact that the impact of uncertainty can not be captured in a static framework. A more realistic approach would be to utilize time series data in modeling how uncertainty, as it increases with time ${ }^{2}$, leads to inefficiency and productivity loss. This was obviously not possible in this study due to unavailability of time series data. The inefficiency model also reveals that larger farms are associated with higher efficiency, though not significant at $5 \%$ level of significance. These results confirm the findings by Sen (1966), Mazumdar (1965), Bardhan, (1973), Feder, (1985), Khandker et al., (1986), and Khandker et al., (1987) that small farms do not use the least-cost input combination. The dummy variable on ethnicity also has a significant effect on farm efficiency. The Indian farmers are relatively more efficient than the Fijian farmers.

\section{CONCLUSION AND POLICY IMPLICATIONS}

This study involves the application of neoclassical production economics theory to Fiji's sugar industry. The primary objective of this study was to investigate ways in which the industry could survive in periods of lower output price. One such 
period may not be too far away as Fiji's sugar industry is expected to enter the world free market. In past years, the free market price has been significantly lower relative to the price Fiji's producers have received from preferential treatment in the EU market. In such a case, efficient allocation of available resources will not only increase crop yields but also can lead to a reduction in average costs. As such, this study is primarily geared towards the estimation of the degree of inefficiency that may exit in Fiji's sugar industry at the farm level and in such a case, to identify the various determinants of inefficiency, which can then form the basis for policy formulation.

Results from this study indicate that there is potential to increase productivity by $5.6 \%$ via increased efficiency (Table 1 ). There are various ways this could be achieved. The move towards plantation agriculture should be made with caution. First, further research needs to be done to verify the hypothesis on efficiency and optimal farm size. Furthermore, the social implications of such moves should also be examined. This move may meet opposition from farm households as amalgamation could lead to their eviction and thus hardship in life. However, a large portion of farmers, may anyway face eviction, after non-renewal of their land leases. Therefore, this may be the opportune time to amalgamate the small farms into large plantations. Another variable that significantly affects efficiency is land class. This suggests that one way productivity on Fijian farms could be increased is via improvements such as; erosion control practices, provision of irrigation and other soil improvement practices that would enhance nutrient retention and uptake. The result pointing to the significant impact of education on farm efficiency verifies the importance of formal education on the long term viability of the agricultural sector. The land reform stage can also look into the future of part-time farmers in the sugar industry.

There are a number of other factors, which were not accounted for in the inefficiency model. Two of these factors include the age of crop (ratoon age) on each farm and the portion of cane harvested after burning. If farmers are encouraged to reduce the age of ratoon and keep more "plant cane", this would significantly boost farm productivity. Furthermore, secondary data have shown that burning cane adds significant losses both to the farmer and the industry. If cane burning prior to harvesting were discouraged, this would contribute to significant increases in farm productivity.

This study investigated the technical efficiency status of Fiji's sugar industry. This study can be taken one step ahead by examining allocative and the overall economic 
efficiency of the farm. This would require time series data, which currently is not available. Time series data can also be used to examine how efficiency has changed over time in the industry.

Appendix A: Estimates of average (OLS) Cobb-Douglas production function

\begin{tabular}{|l|c|c|}
\hline \multicolumn{1}{|c|}{ Variable } & \multicolumn{2}{c|}{ Parameter } \\
\hline Constant & $\beta_{0}$ & 1.132 \\
& & $(0.034)$ \\
\hline Capital & $\beta_{1}$ & 0.042 \\
& & $(0.006)^{*}$ \\
\hline Land & $\beta_{2}$ & 0.663 \\
& & $(0.024)^{*}$ \\
\hline Family Labor & $\beta_{3}$ & 0.042 \\
& & $(0.017)^{*}$ \\
\hline Hired labor & $\beta_{4}$ & 0.013 \\
& & $(0.008)$ \\
\hline Bullock hours & $\beta_{5}$ & 0.045 \\
\hline Tractor hours & $\beta_{6}$ & $(0.011)^{*}$ \\
\hline Fertilizer quantity & $\beta_{7}$ & 0.040 \\
& & $(0.010)^{*}$ \\
\hline Chemical quantity & $\beta_{8}$ & 0.091 \\
& & $(0.014)^{*}$ \\
\hline Log likelihood function & & 0.067 \\
\hline Adjusted $\boldsymbol{R}^{2}$ & & $(0.017)^{*}$ \\
\hline F-statistic for CRS & & 325.02 \\
\hline Figures in parenthesis are & & 0.88 \\
\hline & & 0.054 \\
\hline
\end{tabular}

(a) Figures in parenthesis are standard errors.

(b) * Denotes $5 \%$ level of significance

\section{ENDNOTES}

$1^{\text {st }}$ Class arable: flat, very few limitations, suited to a wide range of crops. Improvement not needed. 
$2^{\text {nd }}$ Class arable: flat to gentle slopes, moderate limitations, similar to $1^{\text {it }}$ class arable.

$3^{\text {rd }}$ Class arable: moderately steep, severe limitations, suited to a narrow range of crops. Improvements required.

Marginal arable: steep slopes, very severe limitations. Major improvements required.

2 The implication here is that as the lease expiry date approaches, the uncertainty with regard to its renewal and the associated risk increases.

\section{REFERENCES}

1. AIGNER, D., LOVELL, C.A.K and P.SCHMID, T. (1977), "Formulation and Estimation of Stochastic Frontier Production Function Models", Journal of Econometrics, 6(1):21-37.

2. BAGI, F.S. and HUANG, C.J. (1983), "Estimating Production Technical Efficiency for Individual Farms in Tennessee", Canadian Journal of Agricultural Economics, 31(2):249-256.

3. BARDHAN, P.K. (1973), "Size, Productivity and Returns to Scale: an Analysis of Farm Level Data in Indian Agriculture", Journal of Political Economy, 81(6):1370-86.

4. BATTESE, G.E. (1997), "A Note on the Estimation of Cobb-Douglas Production Functions When Some Variables Have Zero Values", Journal of Agricultural Economics, 48(2):250-252.

5. BATTESE, G.E. (1992), "Frontier Production Functions and Technical Efficiency: A Survey of Empirical Applications in Agricultural Economics", Agricultural Economics, 7(1):185-208.

6. BATTESE, G.E. and CORRA, G.S. (1977), "Estimation of a Production Frontier Model: With Application to the Pastoral Zone of Eastern Australia", Australian Journal of Agricultural Economics, 21(2):169-179.

7. BATTESE, G.E. and COELLI, T. J. (1995) "A Model for Technical Inefficiency Effects in a Stochastic Frontier Production Function for Panel Data", Empirical Economics, 20(1);325-532.

8. BATTESE, G.E. and COELLI, T.J. (1993) "A Stochastic Frontier Production Function Incorporating a Model for Technical Inefficiency Effects", Working Papers in Econometrics and Applied Statistics, No. 69, Department of Econometrics, University of New England, Armidale. 
9. BATTESE, G.E. and COELLI, T J. (1992) "Frontier Production Functions Technical Efficiency and Panel Data: With Application to Paddy Farmers in India", Journal of Productivity Analysis, 3(2):153-169.

10. BATTESE, G.E. and COELLI, T.J. (1988) "Prediction of Firm-Level Technical Efficiencies With a Generalized Frontier Production Function and Panel Data", Journal of Econometrics, 38(1):387-399.

11. BATTESE, G.E., COELLI, T.J. and Colby T. C. (1989) "Estimation of Frontier Production Functions and the Efficiencies of Indian Farms Using Panel Data From ICRISAT's Village Level Studies", Journal Quantitative Economics., 5(2):327-348.

12. BATTESE, G.E., MALIK, S.J. and GILL, M.A. (1996) "An Investigation of Technical Inefficiencies of Production of Wheat Farmers in Four Districts of Pakistan", Journal of Agricultural Economics, 47(1):37-49.

13. BAUER, P.W. (1990) "Recent Development in the Econometric Estimation of Frontiers", Journal of Econometrics, 46(2):39-56.

14. BRAVO-URETA, B.E. and PINHERIO, A.E. (1993) "Efficiency Analysis of Developing Country Agriculture: A Review of the Frontier Function Literature", Agricultural and Resource Economics Review, 22(1):88-101.

15. BRAVO-URETA, B.E. and PINHERIO, A.E. (1997) "Technical, Economic, and Allocative Efficiency in Peasant Farming: Evidence from the Dominican Republic", Developing Economies, 35(1);48-67.

16. BRAVO-URETA, B.E, and RIEGER, L. (1991) "Dairy Farm Efficiency Measurement Using Stochastic Frontiers and Neoclassical Duality", American Journal of Agriculture Economics, 73(1):421-28.

17. COELLI, T.J. (1992) "A Computer Program for Frontier Production Function Estimation: FRONTIER, version 4.1", Department of Econometrics, University of New England.

18. COELLI, T.J. (1985) "A Generalized Frontier Production for Crosssectional, Time-series Data", Unpublished B.App.Ec (honors) dissertation (University of New England, Armidale, N.S.W).

19. COELLI, T.J. (1995) "Recent Developments in Frontier Estimation and Efficiency Measurement", Australian Journal of Agricultural Economics, $39(2): 219-245$.

20. COELLI, T.J., and BATTESE, G. (1996) "Identification of Factors Which Influence the Technical Inefficiency of Indian Farmers", Australian Journal of Agricultural Economics, 40(2):103-128.

21. DEVADOSS, $\mathrm{S}$ and KROPF, J. (1996) "Impacts of Trade Liberalization Under the Uruguay Round on the World Sugar Market", Agricultural Economics, 15(1):83-96. 
22. FEDER, G. (1985) "The Relation Between Farm Size and Farm Productivity", Journal of Development Economics, 18(2/3):297-314.

23. GREENE, W.H. (1990) "A Gamma-Distributed Stochastic Frontier Model", Journal of Econometrics, 46(1):141-163.

24. GREENE, W.H. (1980) "Maximum Likelihood Estimation of Econometric Frontier Functions", Journal of Econometrics, 13(1):27-56.

25. HESHMATI, A., and KUMBHAKAR, S.C. (1997) "Estimation of Technical Efficiency in Swedish Crops Farms: a Pseudo Panel Data Approach", Journal of Agricultural Economics, 48(1):22-37.

26. HUANG, C.J. and BAGI, F.S. (1984) "Technical Efficiency on Individual Farms in Northwest India", Southern Economic Journal, 51(1):108-115.

27. JONDROW, J., LOVELL, C.A.K, MATEROV, I.S. and SCHMIDT, P. (1982) "On the Estimation of Technical Inefficiency in the Stochastic Frontier Production Function Model", Journal of Econometrics, 19(2/3):233-238.

28. KALIRAJAN, K.P. (1981) "An Econometric Analysis of Yield Variability in Paddy Production", Canadian Journal of Agricultural Economics, 29(1):283-294.

29. KALIRAJAN, K.P. and FLINN, J.C. (1983) "The Measurement of Farm Specific Technical Efficiency", Pakistan Journal of Applied Economics, 28(1):167-180.

30. KALIRAJAN, K.P., and SHAND R.T. (1992) "Causality Between Technical and Allocative Efficiencies: An Empirical Testing", Journal of Economic Studies, 19(2):3-17.

31. KHANDHER, S.R., MESTELMAN, S. and FEENY, D. (1987) "Allocative Efficiency, the Aggregation of Labour Inputs, and the Effects of Farm Size and Tenancy Status: Tests from Rural Bangladesh", Journal of Development Studies, 24(1):30-42.

32. KHANDHER, S.R., MESTELMAN, S. and FEENY, D. (1986) "Farm Size, Tenancy Status and Technology: Production Relationships in Rural Bangladesh", Canadian Journal of Development Studies, 7(2):257-68.

33. KOPP, R.J. and SMITH, V.K. (1980) "Frontier Production Function Estimates for Steam Electric Generation: A Comparative Analysis, Southern Economics Journal, 47(1):1049-1059.

34. LEE, L.F. and TYLER, W.G. (1978) "A Stochastic Frontier Production Function and Average Efficiency: An Empirical Analysis", Journal of Econometrics, 7(2):385-390.

35. LUND, P.J. and HILL, P.G. (1979) "Farm Size, Efficiency and Economies of Size", Journal of Agricultural Economics, 30(2):145-58. 
36. MAZUMDAR, D. (1965) "Size of Farm and Productivity: A Problem of Indian Peasant Agriculture", Economica, 42(126):161-173.

37. MEEUSEN, W. and VAN DEN BROECK, J. (1977) "Efficiency Estimation from Cobb-Douglas Production Functions With Composed Error", International Economic Review, 18(2):435-444.

38. MENSAH, Y.M. (1994) "A Simplification of the Kopp-Diewert Method of Decomposing Cost Efficiency and Some Implications", Journal of Econometrics, 60(1/2):133-144.

39. PITT, M.M. and Lee, L.F. (1981) "Measurement and Sources of Technical Inefficiency in the Indonesian Weaving Industry", Journal of Development Economics, 9(1):43-64.

40. REDDY, M. (1998) Production Economics Analysis of Fiji's Sugar Industry, Unpublished Ph.D dissertation, University of Hawaii.

41. SCHMID,T.P., and Lovell, C.A.K.. (1980) "Estimating Stochastic Production and Cost Frontiers when Technical and Allocative Inefficiency are Correlated", Journal of Econometrics, 13(1):83-100.

42. SCHMIDT, P. and Sickles, R.C. (1984) "Production Frontiers and Panel Data", Journal of Business and Economic Statistics, 2(1):367-374.

43. SEN, A.K. (1966) "Peasants and Dualism With or Without Surplus Labor", Journal of Political Economy, 76(5):425-450.

44. STEVENSON, R.E. (1980) "Likelihood Functions for Generalized Stochastic Frontier Estimation", Journal of Econometrics, 13(1):57-66.

45. TREWIN, R., WEGUO, L., ERWIDODO, and BAHRI, S. (1995) "Analysis of the Technical Efficiency over Time of West Javanese Rice Farms", Australian Journal of Agricultural Economics, 39(2):143-163.

46. VLASTUIN, C., LAWRENCE, D., and QUIGGIN, J. (1982) "Size Economies in Australian Agriculture", Review of marketing and Agricultural Economics, 50(1):27-50.

47. WALDMAN, D.M. (1984) "Properties of Technical Efficiency Estimators in the Stochastic Frontier Model", Journal of Econometrics, 25(1):353-364. 